\title{
PREDIKSI JUMLAH KEJADIAN TITIK API MELALUI PENDEKATAN DERET WAKTU MENGGUNAKAN MODEL SEASONAL ARIMA
}

\author{
Muhammad Alkaff 1), Nandang Eko Yulianto ${ }^{2)}$ \\ 1,2) Program Studi Teknologi Informasi, Fakultas Teknik, Universitas Lambung Mangkurat \\ e-mail: m.alkaff@ulm.ac.id ${ }^{1)}$, nandangekoyulianto@gmail.com ${ }^{2)}$
}

\begin{abstract}
Forest fires are a problem that almost every year occurs in Indonesia, especially in the islands of Sumatra and Kalimantan. Generally, forest fires in Indonesia occur on peat land; this is because, in the dry season, peat land will become very dry to a certain depth so that they will burn quickly. Efforts to tackle forest fires have been carried out through satellite hotspots monitoring. The monitoring of hotspot has been done by NASA (National Aeronautics and Space Administration) with Terra and Aqua satellites through the MODIS (Moderate Resolution Imaging Spectroradiometer) instrument. Data obtained from these satellites from 2001 to 2018 then processed into monthly fire hotspots which are then analyzed using the time series approach using the Seasonal ARIMA (Auto-Regressive Integrated Moving Average) model. This study aims to determine the correlation of the number of hotspot events that occurred with the number of hotspot events at the previous time. The test results show that the Seasonal ARIMA model $(1,0,1) \times(1,0,1,12)$ is the best model for predicting the number of hotspots with an RMSE value of 5.85 .
\end{abstract}

Keywords: Forest Fires, Peatlands, MODIS, Time Series, ARIMA

\section{ABSTRAK}

Kebakaran hutan merupakan permasalahan yang hampir setiap tahun terjadi di Indonesia terutama di pu-lau Sumatera dan Kalimantan. Umumnya kejadian kebakaran hutan di Indonesia terjadi pada lahan gambut, hal ini dikarenakan pada musim kemarau, lahan gambut akan menjadi sangat kering sampai kedalaman tertentu sehingga akan mudah terbakar. Upaya menanggulangi kebakaran hutan telah dilakukan melalui peman-tauan titik api melalui satelit, hal ini telah dilakukan oleh NASA (National Aeronautics and Space Administra-tion) dengan satelit Terra dan Aqua melalui instrument MODIS (Moderate Resolution Imaging Spectroradiometer). Data yang didapatkan dari satelit tersebut mulai dari tahun 2001 sampai dengan 2018 kemudian diproses menjadi jumlah kejadian titik api perbulan yang selanjutnya dianalisa dengan pendekatan deret waktu menggunakan model Seasonal ARIMA (Auto Regressive Integrated Moving Average). Hal ini dilakukan untuk mengetahui korelasi jumlah kejadian titik api yang terjadi dengan jumlah kejadian titik api pada waktu sebelumnya. Hasil pengujian menunjukkan bahwa model Seasonal ARIMA $(1,0,1) x(1,0,1,12)$ adalah model terbaik untuk melakukan prediksi jumlah titik api dengan nilai RMSE sebesar 5.85.

Kata Kunci: Kebakaran Hutan, Lahan Gambut, MODIS, Deret Waktu, ARIMA

\section{PENDAHULUAN}

$\mathrm{K}$ EBAKARAN hutan dan lahan di Indonesia telah lama menjadi krisis lingkungan tahunan yang bahkan dirasakan oleh masyarakat dunia. Kabut asap dan dampak lain yang diakibatkan kebakaran hutan menuntut pemerintah Indonesia untuk segera bertindak guna menyelesaikan permasalahan kebakaran hutan yang kerap terjadi terutama di musim kemarau. Kejadian kebakaran hutan di Indonesia cenderung terkonsentrasi pada konsesi pertanian dan lahan gambut [1]. Potensi kebakaran di lahan gambut dapat menjadi semakin besar jika terjadi pengeringan. Hal ini disebabkan oleh fungsi penyerapan air pada gambut yang sangat kering akan sulit dilakukan karena gambut sudah tidak berfungsi sebagai tanah dan sifatnya sama seperti kayu kering. Pengeringan gambut berdampak pada tingkat kebakaran yang tinggi. Fungsi penyerapan air pada gambut yang sangat kering akan sulit dilakukan karena dalam keadaan tersebut, gambut sudah tidak berfungsi sebagai tanah dan sifatnya sama seperti kayu kering. Sementara itu, ketika kadar air menyusut di musim kemarau, kegiatan pengeringan 
gambut yang dilakukan oleh manusia meningkatkan potensi kebakaran di atas lahan gambut.

Berbagai upaya sebenarnya telah dilakukan oleh pemerintah untuk menanggulangi kebakaran hutan. Akan tetapi, upaya tersebut umumnya difokuskan pada pemadaman titik api yang menjadi penyebab kebakaran. Hal ini tentu saja dilakukan setelah terjadinya kebakaran hutan sehingga penanganannya menjadi kurang efektif karena dampak dari kebakaran hutan akan lebih sulit ditangani ketika kebakaran tersebut telah meluas. Oleh karena itu, diperlukan upaya yang lebih maksimal dari pemerintah agar dapat menanggulangi kebakaran hutan sebelum kejadian tersebut terjadi.

Salah satu upaya tersebut adalah upaya monitoring titik api yang dilakukan oleh LAPAN (Lembaga Penerbangan dan Antariksa Nasional) melalui situs resmi mereka [2]. Situs ini mengambil data real time melalui web service yang disediakan Active Fire Data yang dikelola oleh NASA (The National Aeronautics and Space Administration) [3]. Melalui upaya ini, pemerintah berusaha agar dapat merespon cepat apabila terjadi kebakaran hutan sebelum kebakaran tersebut meluas dan sulit untuk dipadamkan. Akan tetapi, perlu digarisbawahi bahwa hal itu berarti kebakaran telah terjadi di suatu lokasi dan harus segera dilakukan tindakan pemadaman. Oleh karena itu, diperlukan suatu pendekatan baru untuk menangani masalah kebakaran hutan sebelum terjadi. Salah satu cara tersebut adalah dengan melakukan peramalan/prediksi.

Penanggulangan dan pencegahan kebakaran hutan merupakan topik yang banyak diteliti oleh peneliti dari berbagai bidang. Di bidang teknologi informasi sendiri, arah penelitian tentang kebakaran hutan banyak membahas tentang pemetaan risiko dari kebakaran hutan. Pendekatan pemetaan risiko kebakaran hutan antara lain dilakukan dengan wireless sensor [4], [5], unmanned air vehicle (UAV) [6], [7], dan juga dengan menggunakan satelit [8], [9]. Namun, pendekatan yang dilakukan pada penelitian diatas cenderung mengarah pada penanggulangan kebakaran hutan setelah kejadian kebakaran hutan tersebut terjadi. Guna menangani kejadian kebakaran hutan sebelum terjadi diperlukan pendekatan yang bersifat preventif agar kebakaran hutan dapat dicegah sebelum terjadi.

Penelitian untuk mencegah risiko kebakaran hutan dilakukan dengan melakukan prediksi kebakaran hutan yang mungkin terjadi di masa depan. Penelitian yang telah dilakukan antara lain dengan menerapkan metode data mining menggunakan data meteorologi [10]. Penelitian tersebut menggunakan data spasial, temporal, dan data Canadian Fire Weather Index (FWI) serta empat jenis kondisi cuaca. Data-data ini kemudian dimodelkan melalui analisis regresi yang bertujuan untuk melakukan prediksi area kebakaran hutan. Penelitian lain mencoba menerapkan sistem cerdas guna memprediksi kejadian kebakaran hutan dengan menganalisa faktor risiko kebakaran hutan [11]. Namun, belum ada penelitian yang membahas hubungan antara kejadian kebakaran di masa lalu dengan kejadian kebakaran yang terjadi di masa sekarang, padahal data deret waktu merupakan sumber data berharga untuk mengamati tren yang terjadi di masa lalu dan bahkan dapat digunakan untuk memprediksi sesuatu yang terjadi di masa mendatang. Pada penelitian ini akan digunakan data jumlah kejadian titik api perbulan dari tahun 2001 sampai dengan tahun 2018 yang diolah dari data monitoring titik api oleh Satelit Terra yang dimiliki oleh NASA guna melakukan peramalan jumlah kejadian titik api pada tahun berikutnya.

Suatu model yang dibangun dengan data deret waktu akan mencoba mengidentifikasi pola dalam data masa lalu dengan menguraikan tren jangka panjang dan pola musiman kemudian memodelkan pola tersebut untuk memprediksi kejadian di masa depan [12]. Terdapat beberapa metode yang dapat digunakan untuk modelkan data deret waktu antara lain AR (Auto Regressive), MA (Moving Average), ARMA (Auto Regressive Moving Average), ARIMA (Auto Regressive Integrated Moving Average), dan SARIMA (Seasonal Auto Regressive Integrated Moving Average) [13].

SARIMA atau Seasonal ARIMA merupakan modifikasi dari model ARIMA dengan memperhitungkan faktor musiman pada data deret waktu. Pola kejadian kebakaran hutan di Indonesia diasumsikan memiliki pola musiman yang kuat karena titik api umumnya terjadi dan berulang hanya pada musim kemarau. Metode Seasonal ARIMA dirasa sangat relevan untuk memodelkan data deret waktu yang berupa jumlah kejadian titik api di masa lalu guna memprediksi jumlah kejadian titik api yang akan terjadi pada masa yang akan datang. 


\section{Metodologi Penelitian}

Data yang digunakan pada penelitian ini adalah data pemantauan titik api dari Satelit Terra dengan menggunakan instrumen MODIS yang dimiliki oleh NASA (National Aeronautics and Space Administration). Satelit ini dapat memonitor titik api yang terjadi di seluruh dunia secara -real-time selama 24 jam. Terdeteksinya titik api atau hotspot belum tentu berarti bahwa telah terjadi kebakaran hutan di titik tersebut. Hotspot sendiri diartikan sebagai daerah yang memiliki suhu permukaan yang lebih tinggi saat dibandingkan dengan daerah sekitarnya pada ambang batas suhu tertentu. Pada data titik api yang didapatkan dari satelit dengan menggunakan instrument MODIS, hotspot merupakan hasil deteksi suhu panas di suatu wilayah yang dideteksi oleh satelit pada skala ukuran piksel tertentu misalnya $1 \mathrm{~km} \times 1 \mathrm{~km}$. Umumnya, semakin banyak titik api yang terdeteksi pada suatu area, maka semakin besar pula kemungkinan terjadinya kebakaran hutan di area tersebut [14].

Data titik api yang dideteksi oleh satelit Terra memiliki informasi-informasi yang berhubungan dengan titik api tersebut, diantaranya adalah nilai latitude dan longitude tempat terjadinya titik api, tanggal dan waktu terjadinya titik api, confidence level atau tingkat kepercayaan hasil deteksi yang dilakukan oleh satelit Terra, serta informasi-informasi lain yang terkait dengan titik api tersebut [15].

Pada penelitian ini, data titik api diambil pada sebuah area of interest dengan radius sejauh $25 \mathrm{~km}$ dengan titik tengah yang terletak pada kordinat latitude 114.65843 dan longitude -2.57244 yang lokasinya berada pada lahan gambut di pulau Kalimantan. Dari data tersebut hanya diambil dua parameter yaitu tanggal terjadinya titik api dan data nilai selang kepercayaan titik api tersebut.

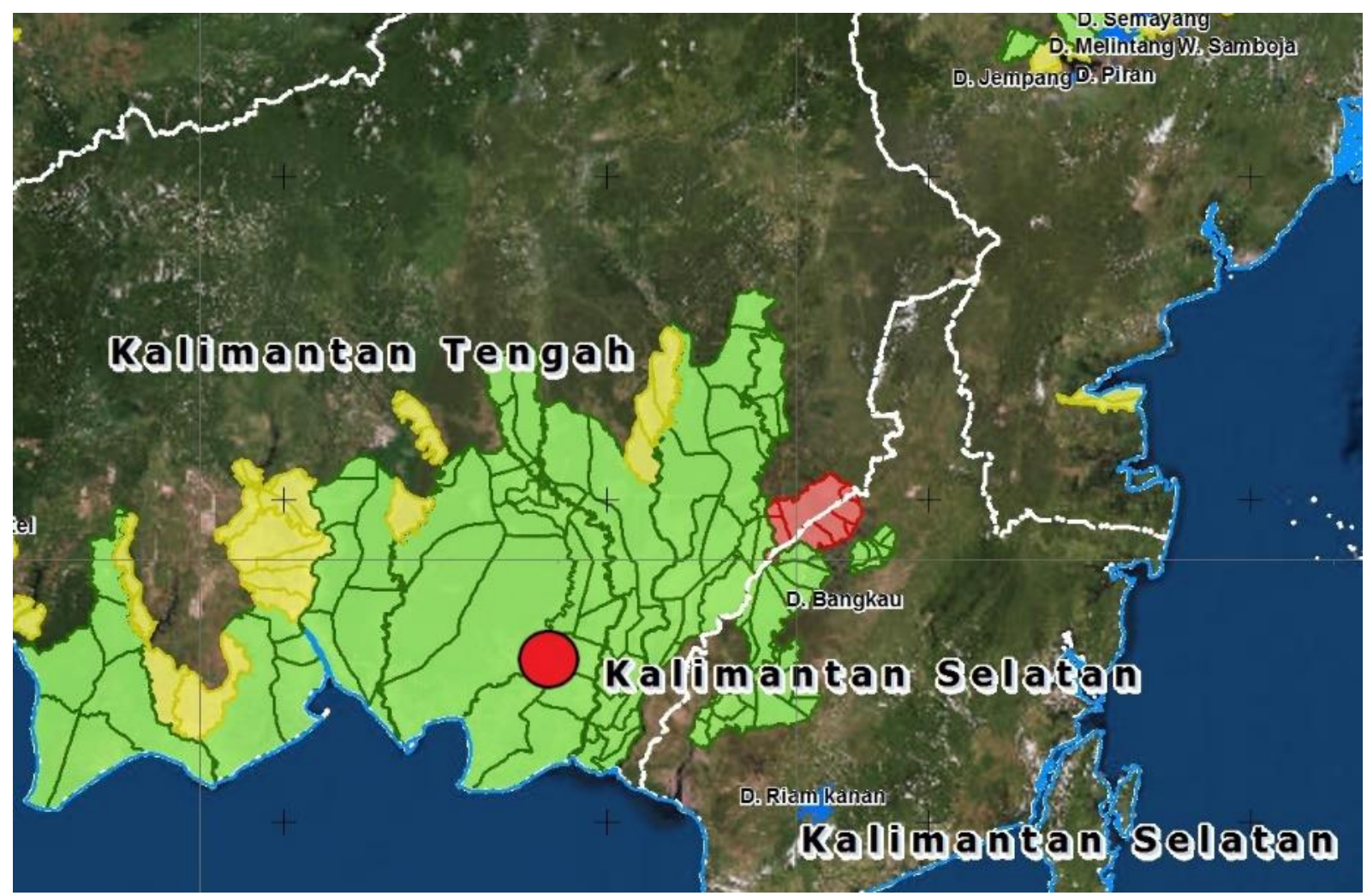

Gambar. 1. Lokasi Area of Interes Pengambilan Data Titik Api

Data yang digunakan pada penelitian ini adalah titik api yang memiliki nilai selang kepercayaan atau confidence level lebih dari atau sama dengan $80 \%$. Hal ini dikarenakan, data titik api dengan nilai selang kepercayaan diatas $80 \%$ merupakan titik api yang dapat diyakini sebagai kejadian kebakaran hutan yang harus segera ditanggulangi secepatnya. Gambar 1 menunjukkan lokasi pengamatan pada penelitian ini dimana lingkaran merah menunjukkan area of interest dimana data jumlah kejadian titik api dengan nilai confidence level lebih dari atau sama dengan $80 \%$ akan diambil.

LAPAN (Lembaga Penerbangan dan Antariksa Nasional) telah mengeluarkan sebuah panduan teknis yang mengatur bagaimana selang kepercayaan dari suatu titik api yang dideteksi menentukan tindakan yang perlu diambil dalam menanganinya. Tabel I menunjukkan makna dari selang kepercayaan dalam 
data yang diambil dari panduan teknis tersebut [14].

TABEL I

MAKNA SELANG KEPERCAYAAN DALAM INFORMASI HOTSPOT

\begin{tabular}{|c|c|c|}
\hline $\begin{array}{c}\text { Tingkat Kepercayaan } \\
\text { (Conf) }\end{array}$ & Kelas & Tindakan \\
\hline $0 \% \leq \mathrm{Conf}<30 \%$ & Rendah & Perlu diperhatikan \\
\hline $30 \% \leq$ Conf $<80 \%$ & Nominal & Waspada \\
\hline $80 \% \leq$ Conf $\leq 100 \%$ & Tinggi & Segera penangglangan \\
\hline
\end{tabular}

Selanjutnya, data tersebut diakumulasikan menjadi data kejadian titik api per bulan dimana ketika suatu data titik api memiliki nilai selang kepercayan lebih dari atau sama dengan $80 \%$ maka dianggap telah terjadi kejadian titik api di tanggal tersebut. Data titik api yang dideteksi dalam kurun waktu 1 bulan akan dijumlahkan sehingga menjadi data jumlah titik api per bulan yang ada pada area of interest. Data bulanan jumlah titik api ini yang kemudian akan dimodelkan menggunakan metode Seasonal ARIMA agar dapat memprediksi jumlah titik api per bulan dalam kurun waktu 1 tahun kedepan. Gambar 2 menyajikan grafik jumlah titik api setiap bulan dari tahun 2001 sampai dengan tahun 2018. Flowchart penelitian ini dapat dilihat pada Gambar 3.

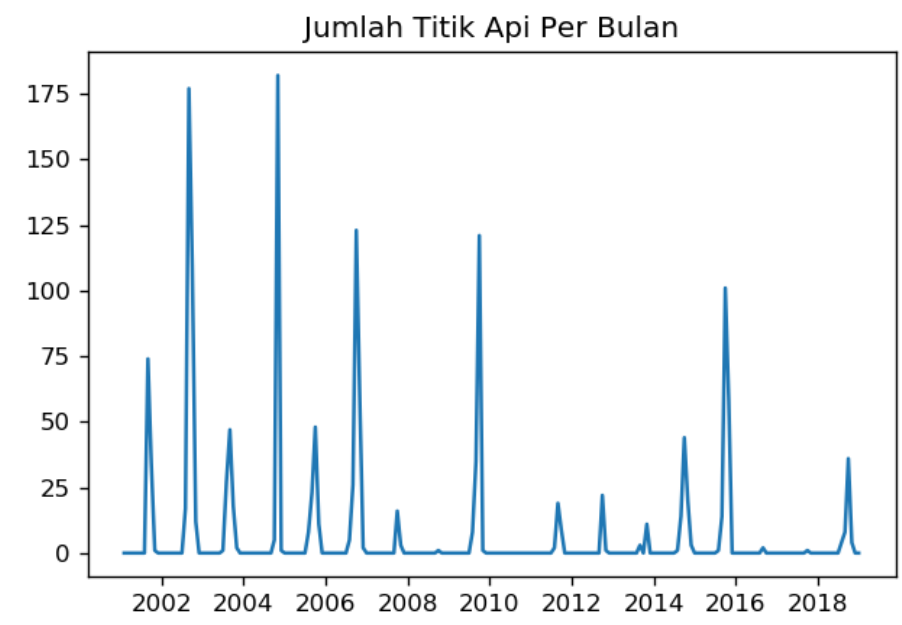

Gambar 2. Data Titik Api Yang Terjadi Dari Tahun 2001 Hingga Tahun 2018

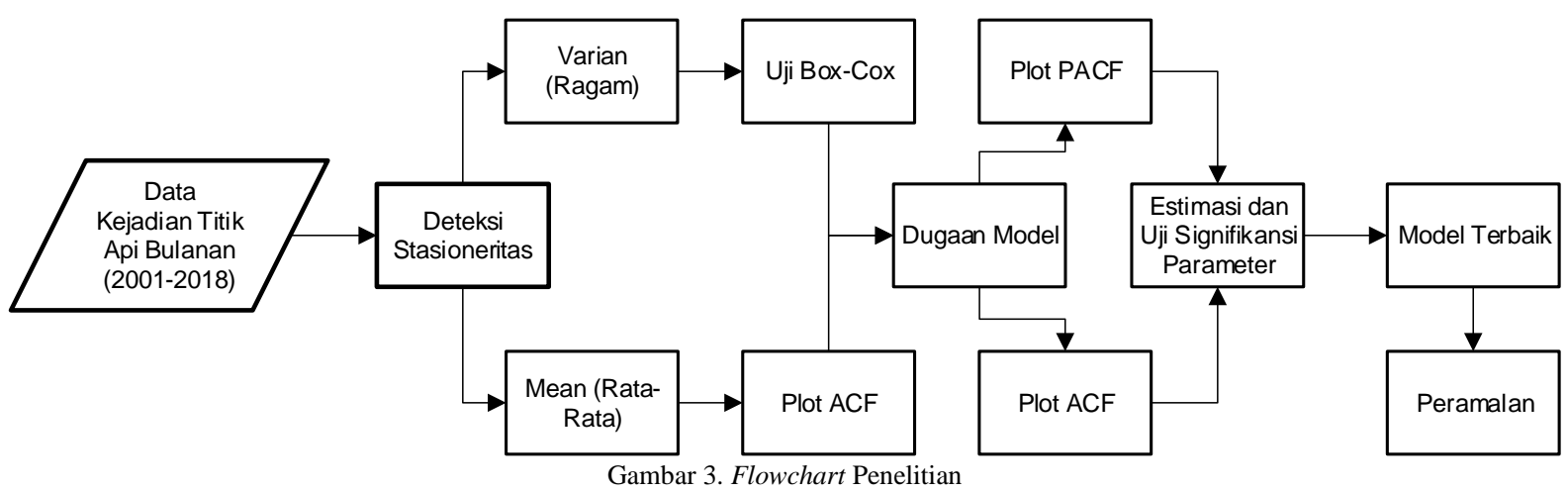

\section{HASIL DAN PEMBAHASAN}

Sebelum dapat dapat dimodelkan sebagai data deret waktu, terdapat beberapa asumsi yang harus dipenuhi, salah satunya ada aturan stasioneritas. Seperti dapat dilihat pada Gambar 2. Nilai 0 yang banyak terdapat pada data dapat mengakibatkan pola data menjadi tidak stasioner. Oleh karena itu perlu dilakukan transformasi ke dalam bentuk lain. Transformasi awal dilakukan dengan menambahkan data awal dengan 10. Hasil transformasi data tersebut dapat dilihat pada Gambar 4 berikut. 


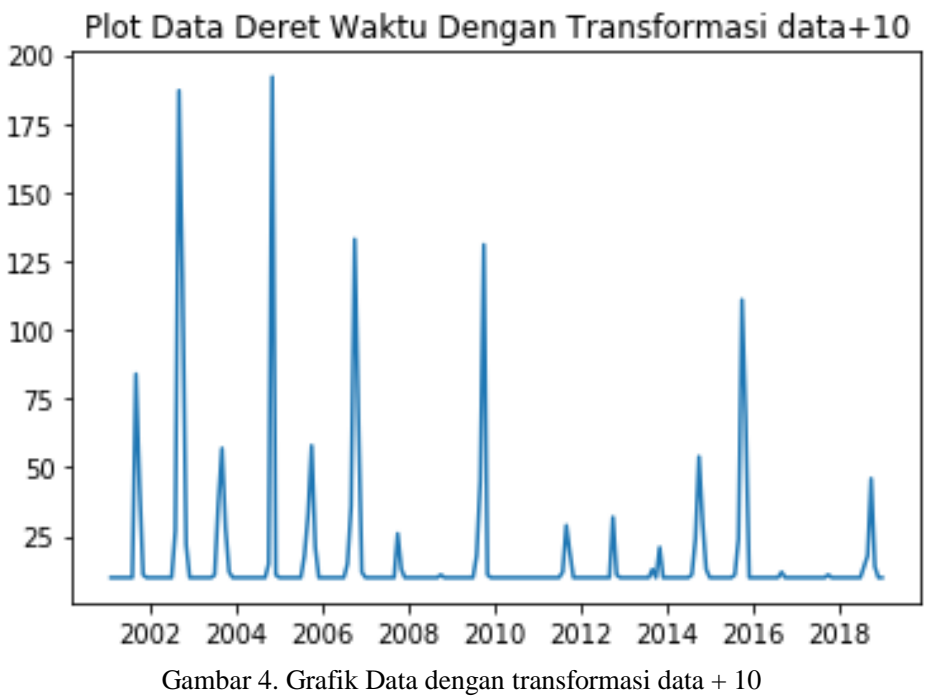

Walaupun plot data di atas menampilkan hasil pola yang masih cenderung naik dan turun stabil di nilai 10, ternyata tidak ada pola tren naik ataupun turun dan juga tidak terlihat pola musiman. Selanjutnya dilakukan pemeriksaan asumsi. Pemeriksaan asumsi yang digunakan dalam penelitian ini adalah dengan metode Box-Jenkins, sehingga asumsi yang harus dipenuhi adalah stasioner dalam ragam dan rata-rata. Untuk mendeteksi kestasioneran dalam ragam dilakukan pemeriksaan melalui uji BoxCox. Pola sebaran data dikatakan telah stasioner dalam ragam apabila nilai rounded value pada tampilan Box-Cox plot menghasilkan nilai 1. Hasil uji menggunakan Box-Cox Plot untuk data yang telah ditransformasi dapat dilihat pada Gambar 5.

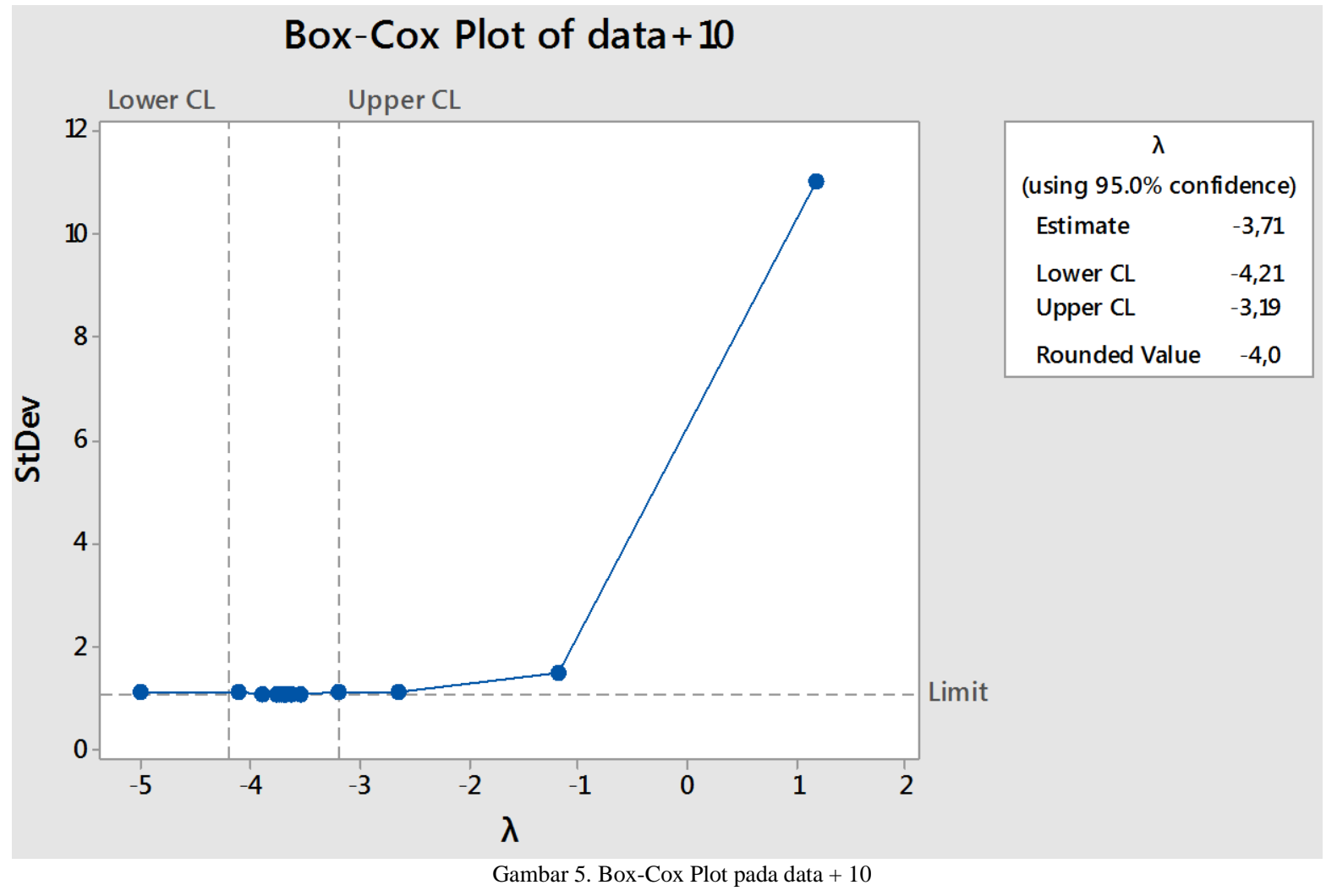

Berdasarkan Gambar 5 di atas dapat terlihat bahwa nilai rounded value yang diperoleh sebesar -4 yang dibulatkan dari nilai lambda sebesar -3.71 . Hal ini menunjukkan bahwa data belum stasioner dalam ragam sehingga harus dilakukan transformasi lagi ke bentuk (data awal +10$)^{-4}$. Selanjutnya diperiksa kembali asumsi kestasioneran dalam ragamnya melalui uji Box-Cox. 


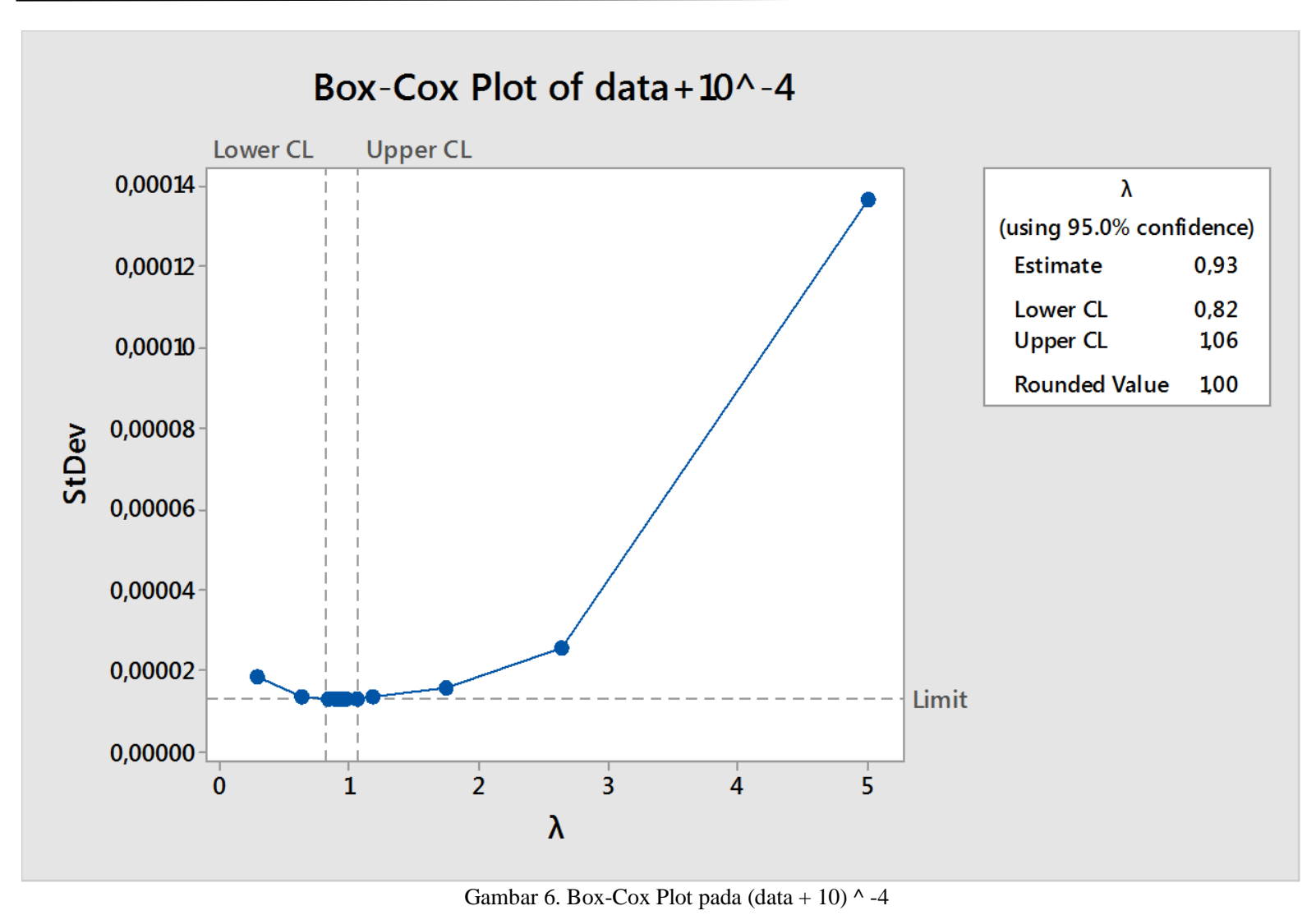

Berdasarkan plot Box-Cox pada Gambar 6, terlihat bahwa data sudah stasioner dalam ragam karena rounded value sudah bernilai 1 (dibulatkan dari nilai lambda sebesar 0.93). Pola data yang telah stasioner dalam ragam terlihat pada data deret waktu tersebut dapat dilihat pada Gambar 7 dibawah ini.

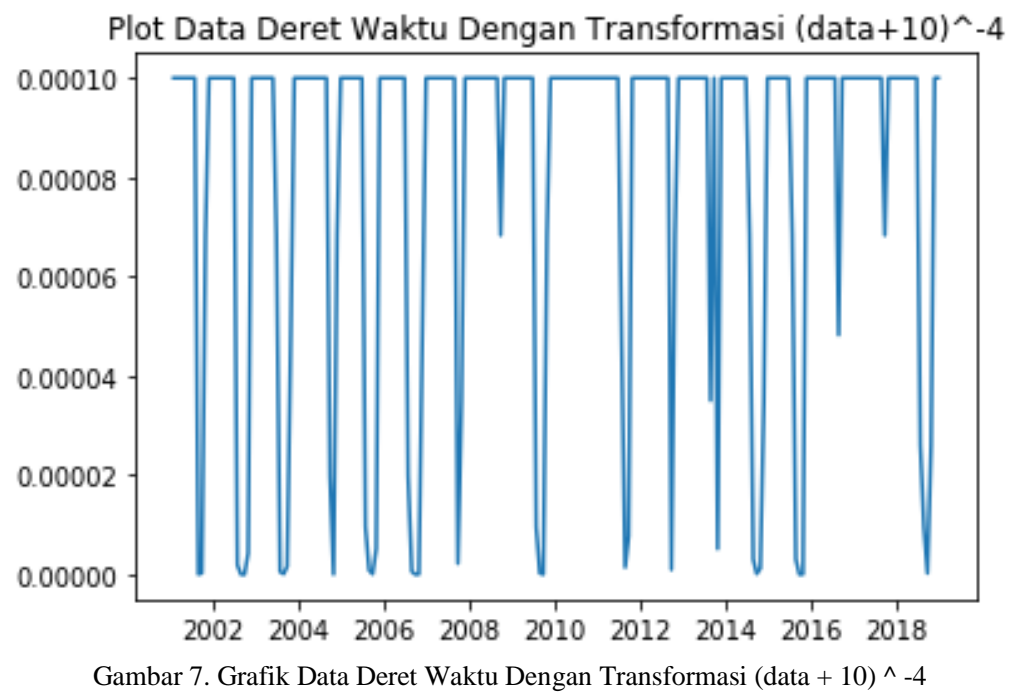

Selanjutnya dilakukan deteksi kestasioneran dalam rata-rata melalui tampilan plot ACF dan PACF. Berdasarkan plot ACF pada gambar 8 dibawah ini, terlihat nilai ACF membentuk pola sinusoidal yang cenderung lambat. Data yang stasioner dalam rata-rata akan menampilkan pola sinusoidal yang cenderung cepat hanya dalam beberapa lag saja. 


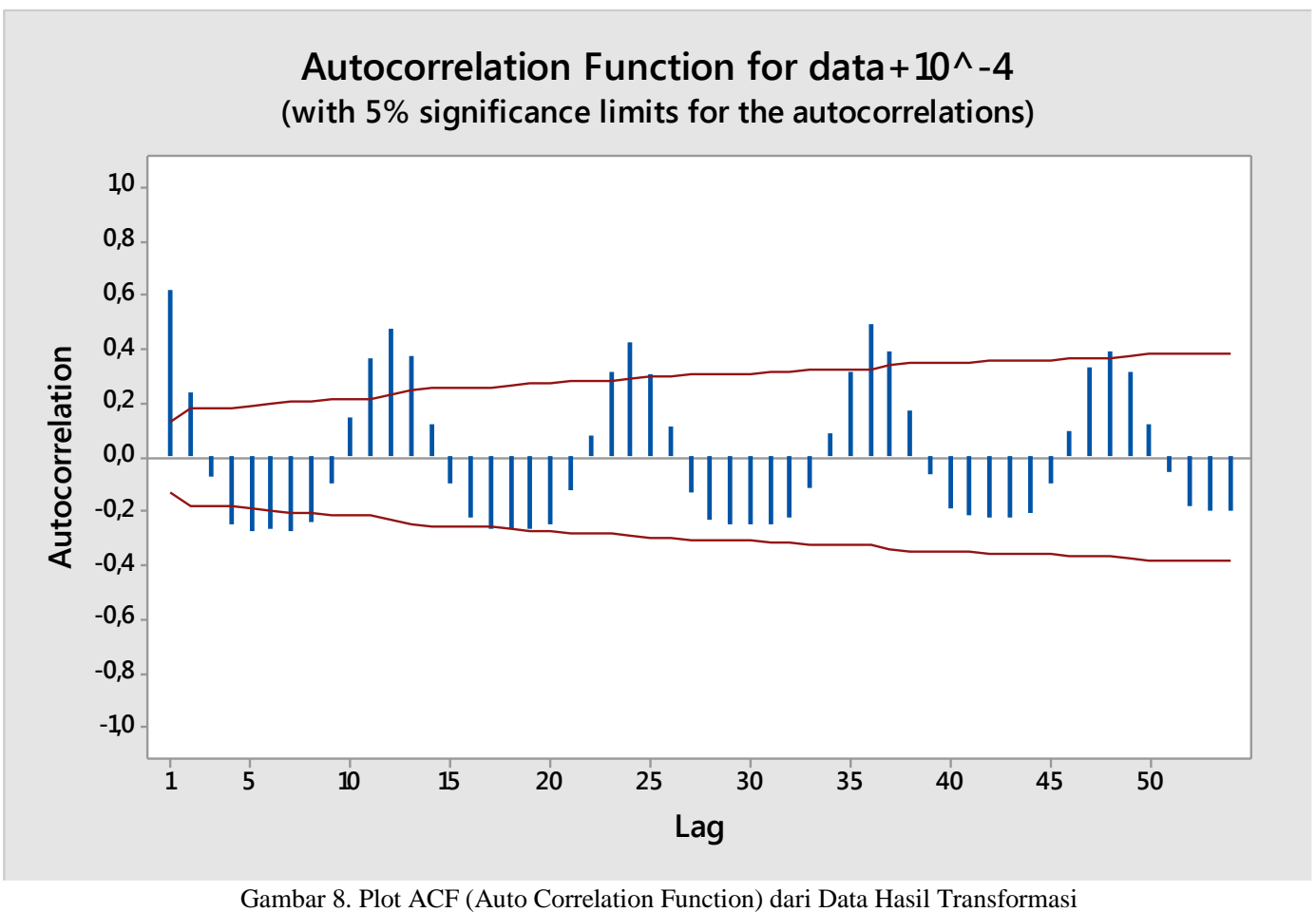

Selain itu, jika dilihat dari plot PACF pada gambar 8, terlihat bahwa nilai PACF masih cut off (terpotong) oleh garis merah di atas dan bawah di beberapa lag yang artinya data belum signifikan stasioner dalam rata-rata. Untuk mengatasi pelanggaran asumsi stasioner dalam rata-rata dapat dilakukan melalui proses differencing.

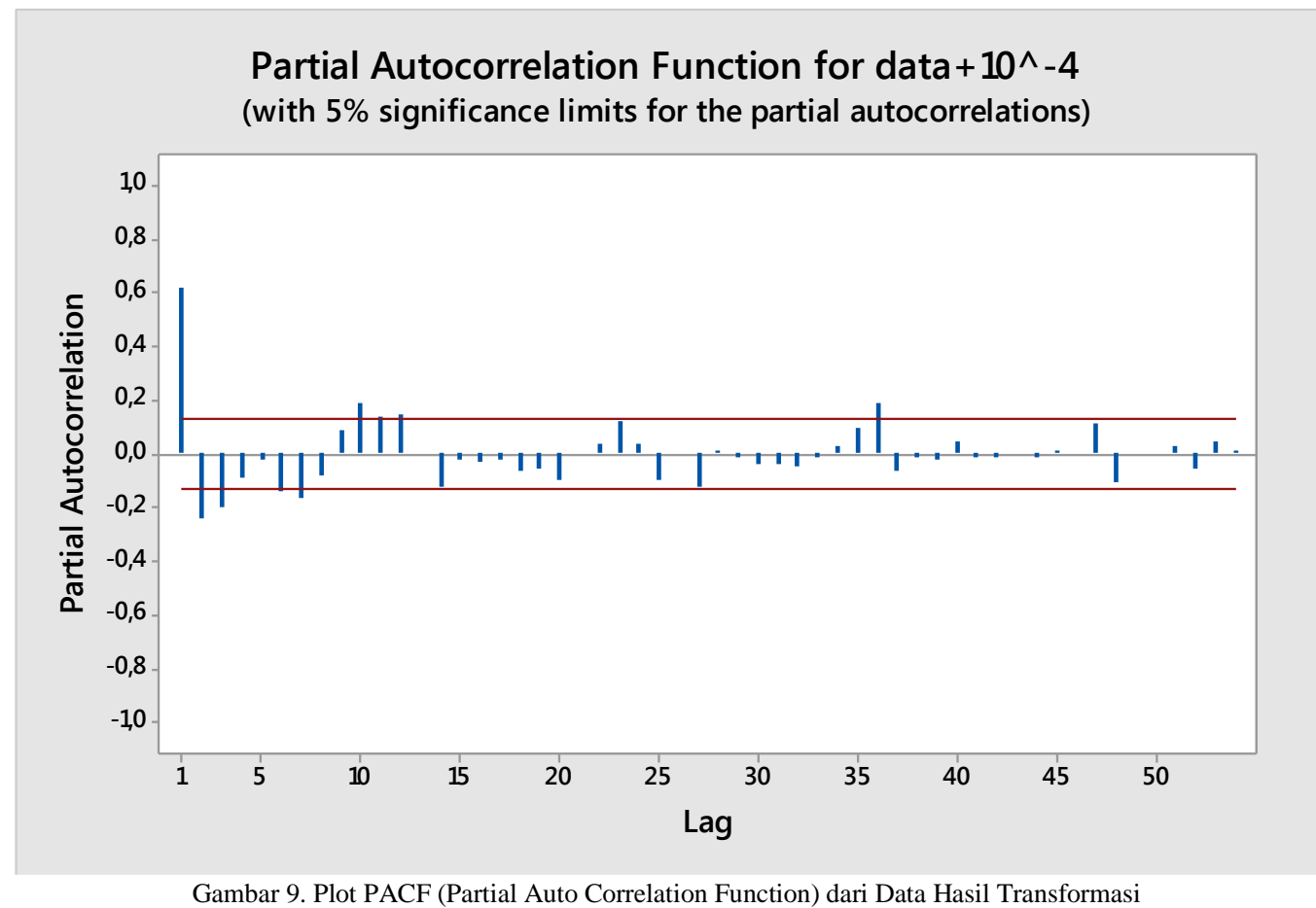

Sebagai simulasi awal, diujicobakan dulu proses differencing 1 kali. Apabila plot ACF dan PACF masih belum menunjukkan tanda kestasioneran dalam rata-rata, maka dilakukan proses differencing sebanyak 2 kali. Begitu seterusnya hingga diperoleh nilai ACF dan PACF yang menunjukkan pola yang sesuai untuk kestasioneran dalam rata-rata. Hasil plot ACF dan PACF setelah dilakukan differencing 1 kali dapat dilihat pada gambar 10 dan gambar 11. 


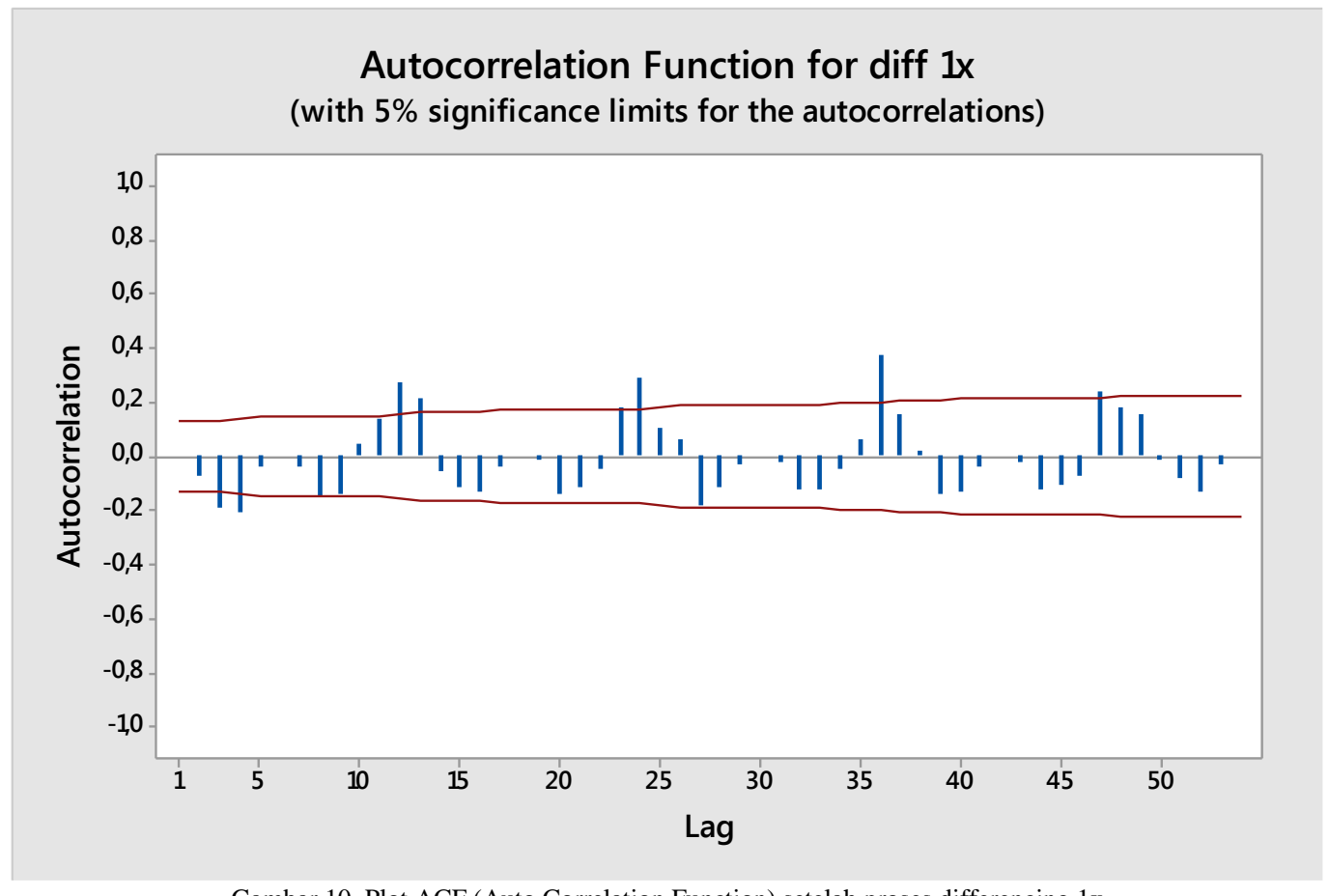

Gambar 10. Plot ACF (Auto Correlation Function) setelah proses differencing 1x

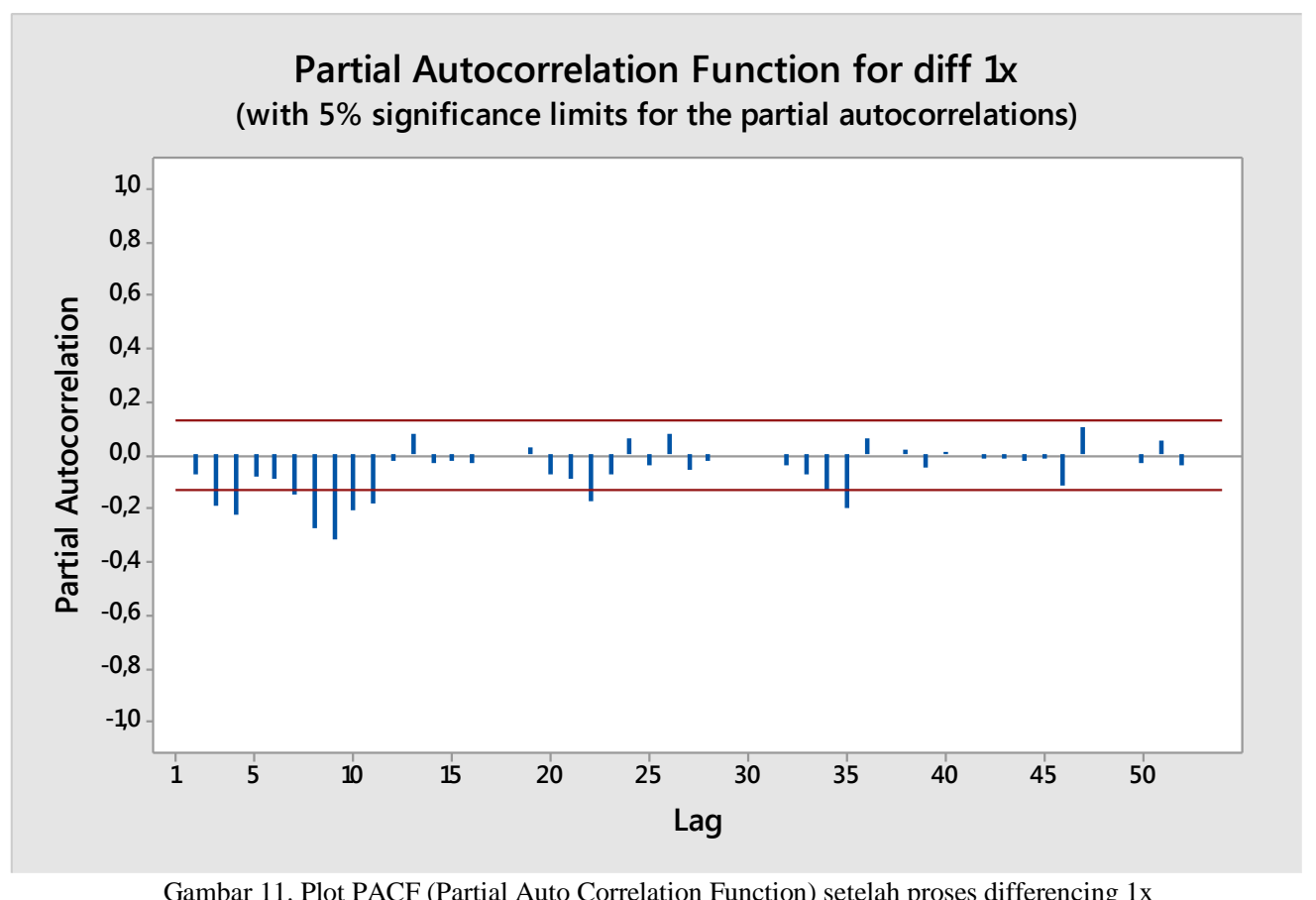

Gambar 11. Plot PACF (Partial Auto Correlation Function) setelah proses differencing 1x

Berdasarkan tampilan plot ACF di atas terlihat bahwa nilai ACF cenderung membentuk pola sinusoidal secara cepat dalam beberapa lag. Sedangkan plot PACF di bawah ini menunjukkan cut off (terpotong) oleh garis merah bawah di beberapa lag. Ini artinya dapat disimpulkan bahwa data sudah stasioner, baik dalam ragam maupun rata-rata.

Selanjutnya adalah proses penentuan model terbaik. Dikarenakan metode ARIMA memiliki beberapa parameter yaitu $p, d, q$ serta parameter seasonal $P, D, Q, m$ maka akan digunakan grid search dalam penentuan model terbaik dengan membandingkan nilai AIC (Akaike Information Criteration) dan BIC (Bayesian Information Criteration). Khusus untuk parameter $\mathrm{m}$ digunakan nilai tetap yaitu 12 dikarenakan telah diketahui bahwa data yang digunakan adalah data bulanan sehingga memiliki pola musiman dengan nilai 12. Pada tabel 2 dapat dilihat 5 model terbaik dengan kombinasi parameter yang berbeda dengan nilai AIC dan BIC terkecil. 
TABEL II

\begin{tabular}{ccc} 
5 MODEL TERBAIK YANG DIHASILKAN MELALUI PROSES GRID SEARCH \\
\hline \hline Parameter & AIC & BIC \\
\hline ARIMA $(1,0,1) \times(2,0,2,12)$ & -3250.832 & -3225.288 \\
ARIMA $(2,0,2) \times(2,0,2,12)$ & -3254.200 & -3222.270 \\
ARIMA $(2,0,2) \times(1,0,1,12)$ & -3258.016 & -3232.473 \\
ARIMA $(1,0,1) \times(1,0,2,12)$ & -3264.667 & -3242.316 \\
ARIMA $(1,0,1) \times(1,0,1,12)$ & -3274.059 & -3254.901 \\
\hline \hline
\end{tabular}

Dari tabel II tersebut dapat disimpulkan bahwa, walaupun perbedaan nilai AIC dan BIC tidak terlalu signifikan, model Seasonal ARIMA dengan kombinasi parameter $(p=1, d=0, q=1) \times(P=1, D=0, Q=1, m=12)$ dapat dianggap sebagai model terbaik karena memiliki nilai AIC dan BIC terkecil dibandingkan model lainnya.

Pengujian model terbaik dilakukan melalui menggunakan metriks Root Mean Square Error (RMSE) dengan melakukan perhitungan selisih nilai hasil prediksi dari model dengan jumlah kejadian titik api yang sebenarnya. Pada gambar 12 dapat dilihat grafik perbandingan hasil prediksi dengan jumlah kejadian titik api yang sebenarnya pada tahun 2016 sampai dengan tahun 2018.

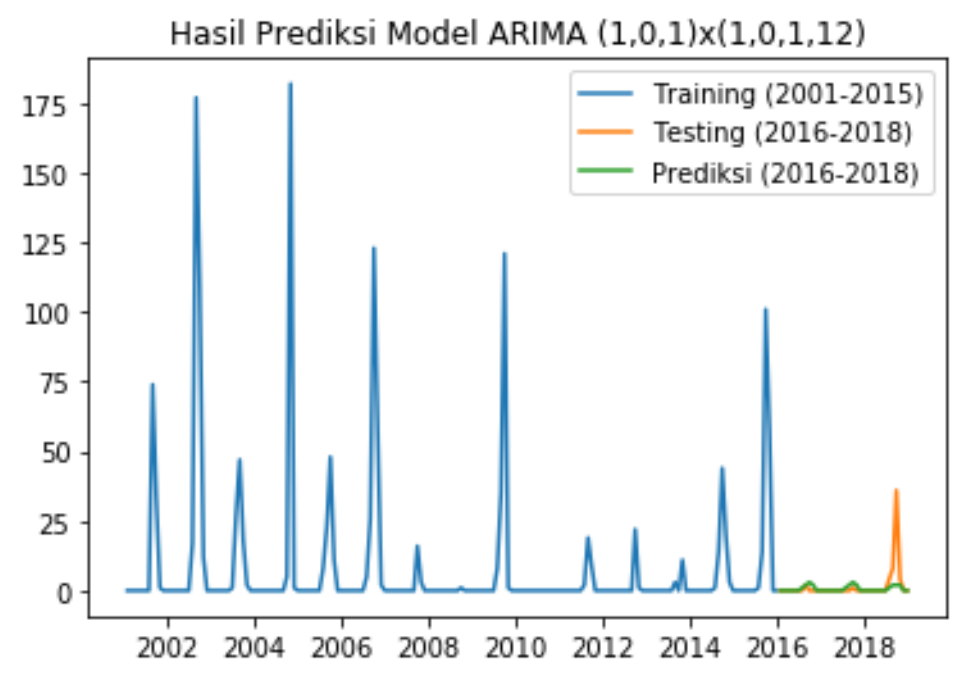

Gambar 12. Grafik Hasil Prediksi Model Untuk Data Titik Api Di Tahun 2016-2018

Melalui plot grafik prediksi pada gambar 12, dapat dilihat bahwa model Seasonal ARIMA $(1,0,1) \times(1,0,1,12)$ mampu menghasilkan trend peramalan yang mendekati nilai kejadian sebenarnya. Namun, untuk kasus dimana terdapat lonjakan kejadian titik api, model yang dihasilkan belum dapat memprediksi jumlah kejadian titik api dengan baik. Contohnya, pada bulan Agustus tahun 2016 terdapat 2 kejadian titik api dan model prediksi juga memberikan hasil prediksi berupa 2 kejadian titik api selanjutnya pada bulan September 2017 hanya terdapat 1 kejadian titik api, namun model memberikan hasil prediksi bahwa terjadi 3 titik api. Akan tetapi, pada bulan September tahun 2018 dimana terdapat 36 kejadian titik api, model prediksi hanya mampu menghasilkan nilai 2 kejadian titik api. Hal ini dapat dipahami karena model yang dihasilkan menggunakan data hasil transformasi yang cenderung mengarah ke asumsi stasionaritas sehingga penyimpangan data hasil prediksi yang dihasilkan menjadi kecil serta tidak mampu menangani lonjakan data yang besar.

\section{IV.KESIMPULAN}

Dari hasil pengujian didapatkan bahwa model yang terbaik adalah Seasonal ARIMA $(1,0,1) \mathrm{x}(1,0,1,12)$ yang menghasilkan RMSE sebesar 5.85. Secara umum, dapat dikatakan bahwa model Seasonal ARIMA memberikan kinerja yang baik dalam menggambarkan trend kejadian titik api yang akan terjadi di masa mendatang. Akan tetapi, nilai prediksi yang dihasilkan pada penelitian ini masih berupa peramalan kejadian titik api bulanan sehingga, akan lebih baik apabila peramalan jumlah kejadian titik api dapat dilakukan dalam skala waktu yang lebih pendek seperti mingguan atau harian. 
Pada penelitian ini, dapat dilihat bahwa model Seasonal ARIMA cukup kesulitan dalam memprediksi lonjakan kejadian titik api, hal ini dikarenakan asumsi stasionaritas oleh data hasil transformasi yang diinputkan. Banyaknya nilai 0 pada data juga menyulitkan dalam pengolahan data serta perancangan model peramalan deret waktu. Oleh karena itu, sebaiknya dapat dilakukan perbandingan dengan menggunakan metode atau permodelan deret waktu lain yang dapat menangani banyaknya nilai 0 pada data deret waktu dengan lebih baik.

\section{DAFTAR PUSTAKA}

[1] A. Chamorro, S. Minnemeyer, and S. Sargent, "Riwayat Kebakaran di Indonesia untuk Mencegah Kebakaran di Masa Depan | Global Forest Watch Blog Global Forest Watch Blog," 2017. [Online]. Available: https://wri-indonesia.org/id/blog/riwayat-kebakaran-diindonesia-untuk-mencegah-kebakaran-di-masa-depan. [Accessed: 21-Jun-2019].

[2] "LAPAN Fire Hotspot." [Online]. Available: http://modis-catalog.lapan.go.id/monitoring/hotspot/index. [Accessed: 28-May-2019].

[3] "FIRMS - Web Services." [Online]. Available: https://firms.modaps.eosdis.nasa.gov/web-services/. [Accessed: 04-May-2019].

[4] L. Yu, N. Wang, and X. Meng, "Real-time forest fire detection with wireless sensor networks," in Proceedings. 2005 International Conference on Wireless Communications, Networking and Mobile Computing, 2005., 2005, vol. 2, pp. $1214-1217$.

[5] J. Zhang, W. Li, Z. Yin, S. Liu, and X. Guo, "Forest fire detection system based on wireless sensor network," in 2009 4th IEEE Conference on Industrial Electronics and Applications, 2009, pp. 520-523.

[6] D. W. Casbeer, Sai-Ming Li, R. W. Beard, R. K. Mehra, and T. W. McLain, "Forest fire monitoring with multiple small UAVs," in Proceedings of the 2005, American Control Conference, 2005., pp. 3530-3535.

[7] D. W. Casbeer, D. B. Kingston, R. W. Beard, and T. W. McLain, "Cooperative forest fire surveillance using a team of small unmanned air vehicles," Int. J. Syst. Sci., vol. 37, no. 6, pp. 351-360, May 2006.

[8] L. Giglio, J. Descloitres, C. O. Justice, and Y. J. Kaufman, “An Enhanced Contextual Fire Detection Algorithm for MODIS,” Remote Sens. Environ., vol. 87, no. 2-3, pp. 273-282, Oct. 2003.

[9] G. Guangmeng and Z. Mei, "Using MODIS Land Surface Temperature to Evaluate Forest Fire Risk of Northeast China," IEEE Geosci. Remote Sens. Lett., vol. 1, no. 2, pp. 98-100, Apr. 2004.

[10] P. Cortez and A. Morais, "A Data Mining Approach to Predict Forest Fires using Meteorological Data," Proc. 13th Port. Conf. Artif. Intell., pp. 512-523, 2007.

[11] A. Alonso-Betanzos et al., "An intelligent system for forest fire risk prediction and fire fighting management in Galicia," Expert Syst. Appl., vol. 25, no. 4, pp. 545-554, Nov. 2003.

[12] S. V. Kumar and L. Vanajakshi, "Short-term traffic flow prediction using seasonal ARIMA model with limited input data," Eur. Transp. Res. Rev., vol. 7, no. 3, p. 21, 2015.

[13] A. ul Ukhra, "Pemodelan dan peramalan data deret waktu dengan metode seasonal arima," J. Mat. UNAND, vol. 3, no. 3, 2014.

[14] Deputi Bidang Penginderaan Jauh; Lembaga Penerbangan dan Antariksa Nasional, "Panduan Teknis Informasi Titik Panas ( Hotspot ) Kebakaran Hutan / Lahan," vol. ISBN 978-6, 2016.

[15] EARTHDATA, “Active Fire Data," Nasa, 2017. [Online]. Available: https://earthdata.nasa.gov/earth-observation-data/near-realtime/firms/active-fire-data. [Accessed: 05-Apr-2019]. 